\title{
É atual crer em Deus? ${ }^{1}$
}

João A. Mac Dowell SJ

A resposta a esta pergunta não parece evidente. Talvez a própria pergunta seja descartada por alguns como inatual. Para enfrentar a questão procederemos em duas etapas. Em primeiro lugar traçaremos um breve quadro da situação contemporânea a respeito da questão de Deus. Em seguida tentaremos interpretar os dados reunidos e assim responder à nossa indagação. A resposta emergirá do confronto entre os sintomas positivos e negativos de um interesse atual pela questão de Deus.

De fato, para quem faz parte da civilização ocidental hodierna, que tende a tornar-se planetária, numa sociedade, que muitos consideram pós-religiosa e pós-cristã, profundamente secularizada, a questão da existência de Deus parece não suscitar nenhum interesse. Até meados do século passado, com a acentuação do processo de secularização da cultura, próprio da modernidade, difundiu-se no Ocidente, especialmente entre as classes superiores, em contraste com a fé religiosa tradicional, um ateísmo militante e agressivo. Baste lembrar, entre muitas outras ocorrências, as leis contra a Igreja e o clero católico do laicismo francês no início do século $\mathrm{XX}$ e as perseguições aos cristãos dos regimes comunistas até meados do mesmo século. Justamente porque se tratava da contestação da crença religiosa da maioria da população, a questão da existência de Deus estava muito presente na consciência das pessoas e no debate público: ou se era por Deus ou contra Deus.

Hoje, porém, o enfrentamento religioso quase desapareceu no mundo ocidental. Muitas pessoas vivem simplesmente sem Deus. Não têm nada contra Deus. Mas, quer exista quer não, Deus para elas não é um problema. A referência a ele é um fato cultural que as deixa inteiramente indiferentes. Trata-se da sociedade pós-moderna, resultante do avanço da secularização, na qual a religião perdeu o monopólio da cosmovisão. Já não é necessário lutar contra Deus. Com a "morte de Deus" no mundo moderno, anunciada por Nietzsche, a perspectiva transcendente perdeu qualquer influência na configuração do sistema social e de suas dimensões políticas, econômicas, científicas, artísticas e culturais. É com o que nos deparamos também no Brasil. A maioria esmagadora da população aqui se declara cristã e diz que acredita em Deus. Mas as estruturas da sociedade e a dinâmica de seu funcionamento (leis, costumes dominantes, mentalidade e valores) não decorrem da fé em Deus, nem a refletem.

O tipo humano atual já não pode ser caracterizado como homo religiosus (cf. Mircea Eliade), mas como homo oeconomicus. O fator econômico é o determinante não só do status social, mas também das decisões políticas, condicionadas pelos interesses do capital financeiro e das empresas transnacionais no contexto do mercado global. As preocupações e

\footnotetext{
${ }^{1}$ Pe. João Mac Dowell, sacerdote jesuíta, atualmente é professor titular da Faculdade de Filosofia e Teologia (FAJE) em Belo Horizonte, proferiu essa Palestra na Abertura do Semestre Letivo do Departamento de Psicologia, por ocasião da celebração dos 50 anos do Programa de Pós Graduação deste Departamento.
} 
interesses prevalentes são intramundanos. Trata-se de assegurar o bem-estar material, mediante um alto nível de consumo, a busca constante de novas satisfações. A vida desenrolase num horizonte de pura imanência, sem qualquer perspectiva de uma existência pós-mortal. Expressões desta postura imanente são as chamadas "Erzatzreligionen", contrafações ou substitutos da religião, que divinizam realidades humanas, mediante atitudes e manifestações rituais de um culto semelhante ao das religiões, com seus ídolos e estrelas no campo do espetáculo e esporte, bem como com o culto do corpo e a consagração incondicional a causas sociais (ecologia, LGBT) e políticas.

Quais seriam as causas da adesão a padrões de vida puramente terrenos, patenteada nas atitudes da maioria das pessoas, mesmo das que se consideram religiosas? Tudo indica que no mundo atual Deus se tornou desnecessário. Nas sociedades tradicionais, a fé em Deus era para muitos uma consolação ante os males e carências da vida terrena. Só Deus podia oferecer um remédio a tantos sofrimentos. Nele o cristão, em particular, depositava a esperança de verdadeira salvação, uma vida melhor, a felicidade plena, em uma existência pós-mortal, simbolizada pelo céu. A impotência humana diante das ameaças da natureza tornava natural o recurso a Deus e a crença na imortalidade da alma.

Hoje, porém, o progresso tecnocientífico e econômico gera nas pessoas a confiança na possibilidade de satisfazer neste mundo as suas necessidades físicas e psíquicas. O ser humano sente-se capaz de resolver os próprios problemas, utilizando as forças da natureza para a melhoria das condições de vida de toda a humanidade. Exemplo disso são as conquistas da medicina. Prevalece assim uma visão materialista da vida, voltada para a satisfação imediata dos desejos. Não é necessário recorrer a Deus, nem esperar um futuro melhor em outra vida.

Outro fator que contribui para a invisibilidade de Deus é o anti-intelectualismo cético e tolerante. A mentalidade dominante é avessa ao questionamento da orientação de vida assumida por cada um. As atitudes diante da existência são assunto pessoal, resultado de opções, que não podem nem têm que ser justificadas racionalmente. Não interessa saber qual é a verdade, mas trata-se para cada um de viver de acordo com o que corresponde aos seus sentimentos e satisfaz os seus anseios imediatos. Aqueles que creem em Deus não se preocupam em comprovar as próprias convicções nem em refutar as objeções contra a sua existência (fideísmo). Os não crentes, por sua vez, não se interessam em discutir ou contestar a posição contrária. Trata-se de um ateísmo tranquilo, que não é contra Deus, mas simplesmente o ignora.

A difusão crescente da mentalidade científica e positivista é mais um elemento desfavorável à fé em Deus. Na medida em que o único processo racional admitido é o método das ciências empíricas não há nem sequer como colocar a questão de Deus. Esta mentalidade modela cada vez mais o pensamento das novas gerações, seja pelo ensino escolar de cunho marcadamente tecnocientífico, seja pelo conteúdo e estilo dos meios modernos de 
comunicação que enfatizam o sensitivo (imagem, som), os dados empíricos, promovendo a superficialidade e o pensamento fragmentário incapaz de articular-se logicamente.

Fixemos agora o outro lado da moeda. Ainda que os fatos apresentados sumariamente até agora sejam indiscutíveis, pode-se também afirmar que o desinteresse atual pelo problema de Deus é apenas aparente. Com efeito, a partir do último quarto do século $X X$, a questão de Deus voltou a ocupar um lugar central no horizonte da cultura e da sociedade em todo o mundo. Já não se pode falar de "morte de Deus" e de "fim da religião". Ao contrário, observa-se um renascimento clamoroso da religiosidade. Falou-se até em "desforra de Deus". De um modo geral, a predição da extinção da religião, como algo ligado a uma mentalidade pré-lógica, própria da infância da humanidade, não se tem confirmado. Cerca de $84 \%$ da população mundial, portanto, a grande maioria, declara pertencer a alguma religião.

No plano individual, entre outros indícios deste novo surto religioso, lembremos o sucesso do pentecostalismo cristão (movimentos carismáticos) e, em geral, dos pregadores televisivos, incluindo os triunfos midiáticos de João Paulo II e do Papa Francisco. Significativa também é a difusão da literatura e das práticas esotéricas e o interesse por acontecimentos "sobrenaturais": visões, milagres, fenômenos parapsicológicos. O misticismo holístico da espiritualidade New Age constitui componente importante da mentalidade pós-moderna.

$\mathrm{Na}$ esfera pública a influência política das religiões tem-se manifestado de maneira crescente nas últimas décadas. É indiscutível a autoridade moral de figuras religiosas, como Martin Luther King, o Dalai Lama, João Paulo II, o Papa Francisco, ainda que muitas vezes não suficiente para promover eficazmente medidas em favor da paz e dos direitos humanos. É também evidente o peso crescente dos fundamentalismos religiosos (não só islâmico) no campo político. Inclui-se aqui p.ex. o tea party com influência notável nas eleições e nas decisões legislativas e judiciárias nos Estados Unidos. Verifica-se ainda uma nova tendência para o estabelecimento de Estados religiosos: a República Islâmica do Irã (1979), as tentativas do Talibã no Afeganistão e mais recentemente do Boko Haram na Nigéria e a restauração do califado sob a designação oficial de Estado Islâmico em partes do Iraque e da Síria. O terrorismo religioso constitui talvez o maior problema político internacional da atualidade. Diante desses acontecimentos, é lícito perguntar com Samuel Huntington se os conflitos mundiais do século XXI não serão determinados justamente pelo fator religioso como "choque de civilizações", ainda que a maioria de tais movimentos políticos, embora se apresentem em nome da religião, não pareçam representar uma autêntica atitude religiosa, como veremos.

Quais seriam as causas desse ressurgimento religioso? Dentre elas pode-se apontar, em primeiro lugar, a decepção com as promessas de solução dos problemas da humanidade pelo desenvolvimento científico e técnico. O mito do progresso contínuo foi desmascarado pelos fatos. As descobertas científicas e invenções tecnológicas (apesar das muitas contribuições para o bem-estar humano), longe de confirmarem as esperanças de um mundo melhor, agravaram a situação de insegurança e miséria. Esta situação resulta, por um lado, do 
mau uso dos novos recursos disponíveis (bombas nucleares, manipulação genética) e mais ainda da restrição dos seus benefícios a minorias privilegiadas com aumento das desigualdades econômico-sociais a nível mundial. De fato o desenvolvimento da tecnociência foi acompanhado de uma atitude antropocêntrica de dominação e desrespeito da realidade (natureza e sociedade) na pretensão de recriá-la à imagem e semelhança do ser humano, segundo seus interesses. Daí p.ex. o comprometimento gravíssimo do meio ambiente em função da exaustão dos recursos não renováveis, da poluição e do aquecimento global.

O desencanto com as promessas de satisfação intramundana dos anseios humanos oferece um campo fértil para a semeadura de propostas de consolação nesta vida ou numa vida pós-mortal, próprias das religiões. O mesmo acontece em virtude da insatisfação com a falta de sentido do estilo de vida contemporâneo. As propostas de um mundo melhor feitas pelas ideologias modernas (cientificismo, liberal-capitalismo, marxismo, solidarismo cristão) puderam oferecer durante certo tempo um ideal, um substitutivo da religião como fornecedora do sentido da vida. A ineficácia dessas propostas em transformar o mundo, tem levado as novas gerações, às mais das vezes, a viver o presente, individualisticamente, sem expectativas e sem um engajamento por um futuro melhor para o conjunto da humanidade. Entretanto, neste novo contexto tornou-se patente para muitos o vazio da existência voltada exclusivamente para a satisfação das necessidades imediatas. Daí a busca de valores que transcendam a banalidade do quotidiano e ofereçam um sentido global à existência. Ora, a religiosidade hoje em alta oferece justamente, por um lado, a imagem de um poder que transcende as limitações humanas, e, por outro, uma resposta imediata aos anseios de satisfação afetiva em um mundo, sob muitos aspectos, hostil.

Sem dúvida, são reais no mundo de hoje tanto os fatores que levam ao declínio da religião como os que favorecem o seu ressurgimento sob novas formas. Como explicar então a ocorrência simultânea dessas duas tendências contraditórias e aparentemente irreconciliáveis? A nosso ver, o espírito da cultura moderna fundada no antropocentrismo racionalista e, portanto, secularizante, longe de ser suplantado hoje por um novo pensamento e atitude de vida, tende a impregnar cada vez mais a humanidade em termos globais. Não rejeitamos, pelo contrário, os ideais propostos originariamente pela modernidade, liberdade, igualdade e fraternidade, bem como a valorização da razão e o desenvolvimento da ciência e da técnica. Entretanto, todo esse edifício foi construído sobre bases inconsistentes, a absolutização do humano e da racionalidade instrumental. É o que chamamos de espírito da modernidade, que deturpa e contamina as suas realizações. De acordo com esta interpretação, a chamada pósmodernidade não constitui uma ruptura com a era moderna. Representa antes um estágio mais avançado do processo de modernização. As oposições que a caracterizam, sentimento versus razão, relativização versus absolutização, subjetividade versus objetividade, autenticidade versus autocontrole, gratuidade versus eficácia, consumo versus produção, são reações à unilateralidade da modernidade, mas se situam no mesmo plano da imanência antropocêntrica. 
Com a derrocada dos valores absolutos que ainda sustentavam o edifício da cultura moderna, resta apenas um absoluto, o indivíduo humano, seus interesses e satisfações.

Ora se o mundo atual, pós-moderno, caracteriza-se como uma fase mais radical do processo de modernização e, portanto, de secularização, como explicar a persistência e mais ainda a nova relevância do fenômeno religioso na vida dos indivíduos e da sociedade? Como conciliar o caráter secularizado da cultura atual, com a difusão da fé em Deus e o vigor das manifestações religiosas nos nossos dias?

A resposta a esta questão decisiva envolve duas afirmações complementares, que procuraremos explicar e justificar a seguir. Por um lado, a atitude religiosa e a referência ao divino persistem na sociedade secularizada contemporânea, porque correspondem a uma estrutura fundamental da existência humana, que nenhum contexto cultural por mais adverso que seja pode simplesmente anular. Por outro lado, o contexto cultural secularizado constitui um óbice formidável à atitude religiosa enquanto referência a um divino transcendente. Seria como florescer em um ambiente desértico.

Ainda prescindindo da validade da fé em Deus, é possível determinar, interrogando pessoas de fé, em que consiste a autenticidade dessa atitude diante da vida. A resposta pode ser formulada aproximadamente nos seguintes termos. Trata-se de uma percepção específica do mistério da existência. Nem todos fazem, pelo menos, expressamente tal experiência. Mas quem a faz compreende que não é, por assim dizer, o dono de sua existência, mas que ela lhe é oferecida como um dom. Compete-lhe acolhê-lo responsavelmente em sua liberdade, orientando-a segundo uma verdade e um bem que o ultrapassam e o comprometem, ao requerer a sua adesão.

Evidentemente, esta é uma das alternativas de resposta à questão inevitável sobre o sentido da vida humana, da própria vida de cada um. Esta questão pode ser respondida também numa perspectiva antropocêntrica, segundo a qual o ser humano e seu mundo têm em si mesmos a sua razão de ser. Nesse caso, a razão humana é virtualmente capaz de compreender e explicar a realidade no seu todo. E cada um tem direito de dispor de sua vida a seu bel prazer, sem respeitar qualquer limite. Esta autossuficiência leva sem dúvida à perda do senso do mistério.

É importante, porém, distinguir entre a atitude existencial da pessoa e as suas afirmações expressas a respeito desta questão fundamental. Com efeito, alguém pode reconhecer implicitamente sua dependência de algo transcendente e procurar viver à luz dessa realidade, mas por motivos teóricos, psicológicos ou pedagógicos não ser capaz de reconhecêlo expressamente, ou, em outras palavras, de afirmar a existência de Deus. O mais frequente talvez seja que esta recusa se deva a que a ideia que alguém recebeu e se faz de Deus seja incompatível com sua experiência existencial. Por outro lado, alguém pode afirmar a existência de Deus, considerar-se crente, pertencendo ou não a uma instituição religiosa, sem, todavia, comprometer-se de algum modo com o que tal afirmação significa em si mesma. 
Fica claro, portanto, que a verdadeira fé em Deus envolve e compromete toda a existência. Muitas pessoas dizem que creem em Deus, p.ex. no Deus cristão, simplesmente porque foram criadas numa família ou num ambiente no qual se professava esta fé, sem nunca terem assumido pessoalmente a sua crença. Trata-se de uma fé por convenção social, ou seja, de uma afirmação de Deus de caráter superficial, por ouvir-dizer, sem consequências práticas. Não é desse tipo de afirmação de Deus que falamos aqui, mas de uma convicção pessoal, sob a forma de um compromisso existencial, baseado em uma experiência peculiar. Com efeito, na medida em que alguém reconhece efetivamente Deus como sentido último de sua existência, não pode deixar de procurar viver de acordo com esta fé, mesmo que não seja plenamente coerente com sua própria convicção.

Como se disse, a fé em Deus é uma das duas respostas básicas à questão do sentido da existência humana. Entretanto, Deus não é percebido pelo homem religioso apenas como o valor que preenche as suas aspirações mais profundas e dá sentido à existência. Ele é reconhecido, antes de tudo, como uma grandeza misteriosa, mas claramente dada, que transcende qualquer pergunta ou desejo humano. Este reconhecimento desperta uma atitude gratuita de respeito e admiração, mas, por isso mesmo de encanto e plenificação, atitude, que na linguagem religiosa é designada, em geral, como "adoração". É porque é experimentado em si mesmo como mistério absoluto, indisponível e merecedor de obediência e serviço incondicional por parte do ser humano, que Deus pode preencher a aspiração humana de felicidade e não vice-versa. Se não fosse vivenciado como plenitude absoluta não seria capaz de satisfazer a busca humana de sempre mais. Neste sentido, quem crê em Deus experimenta, por um lado, a precariedade de sua existência e de toda a realidade humano-mundana e, ao mesmo tempo, o mistério que a envolve e atrai, requerendo, ao mesmo tempo, submissão e confiança.

A fenomenologia da religião constata que para o homo religiosus o divino é uma realidade indiscutível. Cabe à reflexão filosófica demonstrar se este divino, que se apresenta na experiência religiosa e é representado de diferentes formas nas diversas religiões, é projeção ilusória das aspirações do ser humano ou constitui a realidade primeira, que funda a existência do mundo e é a meta de sua busca de verdade e bem. Não é possível realizar aqui, mesmo sumariamente, tal investigação. Entretanto, para justificar a persistência da religiosidade no clima inóspito da secularidade moderna basta mostrar que ela constitui uma dimensão essencial do ser humano. Ora, tal posição, ou seja, a afirmação da dimensão religiosa da existência humana, que não implica por si mesma a existência de Deus, é aceita hoje por grande parte dos estudiosos da filosofia ou das ciências da religião, ainda que não crentes. Como religião institucionalizada ou como sentimento religioso individual, a raiz religiosa ínsita no fundo do espírito humano tende continuamente a brotar.

\footnotetext{
- Nos parágrafos seguintes utilizamos frases que se encontram quase literalmente no nosso artigo: Experiência religiosa e cultura moderna, in: Interações - Cultura e Comunidade, v.3 n.4, 2008, p.17-36.
} 
Com base nesta afirmação e na análise da fé em Deus como experiência do mistério, cabe agora examinar as características da religiosidade contemporânea em vista de nossa pergunta inicial sobre a atualidade da fé em Deus. O ressurgimento religioso das últimas décadas deu-se segundo duas vertentes principais: o fundamentalismo religioso, que se volta para o passado, e os chamados novos movimentos religiosos, como a New Age, que apontam para o futuro na busca de expressões inéditas do sentimento religioso, explorando novas potencialidades da mente humana numa perspectiva holística. Trata-se por um lado da resposta à necessidade de segurança existencial, pessoal e coletiva, face ao racionalismo crítico com sua relativização de todos os valores; por outro, da busca de novas experiências que venham compensar a monotonia do fluxo contínuo de novidades rotineiras e sensações passageiras.

Os traços apenas esboçados destas formas da religiosidade contemporânea, apesar de seus evidentes contrastes, apontam para um fundamento comum. Trata-se nos dois casos de uma reação ao fenômeno da secularização e, de um modo geral, à racionalização e funcionalização da vida moderna, Este quadro cultural deixa insatisfeitas tanto a dimensão afetiva da pessoa humana, como a sua necessidade de dar um sentido global à própria existência. Destarte, as expressões religiosas contemporâneas demonstram que o sistema cultural dominante, apesar de seu caráter secularizado, não consegue abafar totalmente o sentimento religioso. Pelo contrário, ele até o promove, segundo a lei de ação e reação, mas também o configura segundo seus parâmetros individualistas e egocêntricos.

O caráter reativo do surto atual de religiosidade pós-moderna indica, portanto, que ela está enredada nos laços da própria modernidade à qual se opõe. Na medida em que a modernidade implica a dessacralização do mundo, torna-se problemática uma autêntica experiência do divino no contexto da cultura atual. A vida social nas suas várias dimensões, saber, trabalho, lazer, política, etc. não oferece apoio, nem muito menos incitamento para a experiência religiosa, através de símbolos e situações favoráveis à sua eclosão. As realidades humanas mais significativas, como nascimento, morte, amor, integradas num sistema interpretativo racionalista e plenamente funcionalizadas, carecem de qualquer sentido de mistério. Mais radicalmente, a natureza e a sociedade, submetidas aos ditames do sistema tecno-capitalista-midiático, perdem inteiramente o caráter de "meio divino" (expressão de Teilhard de Chardin), i.e. de mediadoras de um encontro com o transcendente.

$\mathrm{Na}$ verdade, as novas formas de religiosidade mostram-se, em última análise, incapazes de exprimir uma autêntica relação do ser humano para com o divino transcendente. Trata-se da religiosidade que é possível, enquanto manifestação da abertura essencial do ser humano ao divino, numa sociedade secularizada, racionalista, subjetivista e pragmática, onde o autêntico sagrado já não tem vez. Os próprios sintomas de mudança na atitude religiosa surgem no bojo de um sistema que continua a avançar na linha da imanência do horizonte existencial, do subjetivismo relativista e da racionalidade tecnocientífica. São válvulas de 
escape que, longe de inverter o curso da história atual, contribuem indiretamente para sua confirmação. Como se viu, a verdadeira experiência de fé é absolutamente gratuita na sua origem divina e na sua resposta humana. Longe de encerrar a pessoa na própria subjetividade, como um meio à sua disposição, para satisfazer as necessidades de segurança e conforto espiritual, ela irrompe espontaneamente na consciência e arranca o ser humano de sua autossuficiência e autossatisfação para lançá-lo no mistério insondável do outro divino. Não se trata, portanto, de um "sobrenatural", que satisfaça a curiosidade e cause sensação, mas de algo que transcende todas as expectativas e faz perder o chão familiar da vida quotidiana.

A nova religiosidade, pelo contrário, tende a instrumentalizar o absoluto divino, subordinando-o à satisfação do sentimento religioso e à aspiração de realização e gratificação pessoal. O surto religioso atual, longe de abalar o império da razão instrumental e os fundamentos da cultura tecnomediática, é determinado por este contexto cultural, tanto na sua origem como nas suas características. Enquanto o motivo da autorrealização imanente, alcançada pelo esforço humano, prevalecer sobre a gratuidade soberana do dom divino e da sua acolhida não será possível desenvolver uma atitude religiosa autêntica. Em outras palavras: a experiência religiosa genuína é incompatível com o antropocentrismo moderno. No naufrágio generalizado dos valores não resta senão um único sagrado: o próprio "eu". Tudo mais é instrumento para a realização do indivíduo e sua felicidade imediata. É lícito perguntar se esta religiosidade egolátrica não constitui de fato um ateísmo disfarçado.

À conclusão inquietante de nossa análise sobre a situação da religião no mundo de hoje, é preciso acrescentar algumas ressalvas fundamentais, que encaminham a resposta à nossa questão inicial sobre a atualidade da fé em Deus.

As considerações feitas questionam evidentemente a interpretação da situação religiosa atual, própria da pós-modernidade, como um "retorno da religião", pelo menos, no sentido de uma inversão do movimento de secularização da sociedade. Todavia, para quem rejeita, como nós, o determinismo histórico, a tendência cultural secularizante não constitui uma fatalidade. Ela pode ser superada, um dia, por uma nova abertura da cultura globalizada ao transcendente divino, abertura que pertence, em princípio, à própria condição humana. A secularização não é um fenômeno irreversível. Entretanto, os fenômenos analisados não permitem afirmar que a humanidade esteja encetando uma fase cultural nova e mais positiva do ponto de vista religioso. Apesar de certos indícios promissores, o contexto global da vida contemporânea continua avesso à verdadeira atitude religiosa.

Como se viu, a incompatibilidade com a experiência religiosa autêntica é própria da cultura moderna e pós-moderna, enquanto secularizada. $\mathrm{Na}$ verdade, de um ponto de vista global, a modernização é um processo ainda em curso, que afeta em graus diversos as diferentes sociedades. De fato, a sociedade humana, no seu conjunto, e a sociedade brasileira, em particular, não estão plenamente secularizadas. Por outro lado, como se viu, cabe ao divino a iniciativa na sua manifestação, que não pode ser simplesmente atrelada a fatores culturais. 
Não se exclui, portanto, que indivíduos isolados ou agrupados em comunidades possam fazer hoje uma verdadeira experiência religiosa, na medida em que escapem aos tentáculos da cultura moderna. Tratar-se-á, porém, de uma atitude contracultural. Ela não implica necessariamente a fuga da civilização e um refúgio na natureza com a adoção de estilos de vida pré-tecnológicos, mas exige certamente uma resistência árdua ao espírito da modernidade e aos seus antivalores.

Nesta perspectiva, retomamos finalmente a nossa pergunta: é atual crer em Deus? À luz do que foi explanado, a resposta é clara, ainda que diferenciada.

A religiosidade vigente nas suas formas especificamente pós-modernas não corresponde a uma autêntica fé em Deus. Sob esse aspecto, portanto, crer em Deus não é atual.

Por outro lado, a verdadeira fé em Deus, enquanto incompatível com a tendência religiosa contemporânea, condicionada pelo espírito moderno, e, portanto, enquanto contracultural, também nesse sentido, não é atual.

Entretanto, a encarnação do ser humano na história e nas culturas não é absoluta. $O$ espírito humano na sua abertura para o todo é capaz de transcender, avaliar e criticar as manifestações da sua cultura. Neste sentido, crer em Deus, enquanto resposta à manifestação de Deus numa experiência, que supera os condicionamentos da mentalidade moderna, é sobremaneira atual: por um lado, corresponde ao que há de mais fundamental e permanente no espírito humano; por outro, constitui a resposta a um apelo, que ressoa no mais íntimo de nosso ser, o apelo a contribuir para libertar o mundo dos impasses da modernidade, dando testemunho da verdade. 